only $20 \%$ of Spanish hospitals report postdischarge surveillance for SSI. Finally, the continued collaboration of surgeons, hospital pharmacists, hospital epidemiologists, and infection control practitioners is of paramount importance for the quality improvement of the National Health System. ${ }^{8}$

From the Hospital Clinic of Barcelona, University of Barcelona, and the August Pi $i$ Sunyer Biomedical Research Institute (IDIBAPS), Barcelona, Spain.

Address reprint requests to Antoni Trilla, MD, MSc, Hospital Epidemiology \& Health Services Research Unit, Hospital ClinicIDIBAPS, Villarroel 170, 08036-Barcelona, Spain.

This work was supported in part by a research grant from GlaxoWellcome and by a research grant from the Spanish Health Research Found (FIS Grant \# 98/1391). This paper was presented at the 1996 American Society of Health-Care Pharmacy Mid-Year Meeting, December 1996. New Orleans, Louisiana; abstract Intl-20. Hospital Pharmacy Antimicrobial Prophylaxis Study Group Members: Rosa Anton, Pedro Cervera (Alicante); Elvira Gea (Andorra); Aparicio Antuña, Francisco Nieto, Maz Paz Sacristán (Asturias); Clara Agustí, Joan Altimiras, Ana Ayestarán, Maria A. Carceller, Tomás Casasin, Isabel Castro, Roser Busquets, Ma Queralt Gorgas, Santiago Grau, Mararmen López, José Miralles, Josep Monterde, Magda Montserrat, Agustí Perelló, Carme Permanyer, Ramón Pla, Jaime Poquet, Cristina Roure, Mercedes Sora, Manuela Velazquez (Barcelona); Felipe Navarro (Bilbao); Juan Chico (Burgos); Pilar Tejada (Cáceres); Mercedes Izquierdo (Castellón); Marta Arteta, Juan C. Valenzuela (Ciudad Real); Andrés Castaño (Eivissa); $M^{a}$ José Buisan, Josefina Camós, $M^{a}$ Antonia Rafart, Elisenda Flotats (Girona); Angeles García .(Guadalajara); Antonia Casas, Maria Outeda, José Vila (La Coruña); MáDolores Velazquez, Elena Castellanos, Alicia Diez, Bartolomé Dominguez (Las Palmas); Montse Navarro, María García (Lleida); Alberto Alfaro, $M^{a}$ Jose Martinez, $M^{a}$ Carmen Obaldía, $M^{a}$ Fernanda Hurtado (Logroño); Lourdes Armentia, Soledad Gonzalez, Gloria Hervás, Paloma Izquierdo, Pilar Sosa (Madrid); Carmen Gállego, Begoña Muros (Málaga); Olga Delgado (Mallorca); MáTeresa Antequera, $M^{a}$ Mar Soler (Murcia); Luciano Martinez (Orense); Joaquin Giráldez (Pamplona); Leonor Munell, Ana García (Santander); Alvaro Aguirre, Majesús Gayán (San Sebastián); José R. Avila (Sevilla); Majesús Gallart, Francesc Paez, $M^{a}$ Angels Vidal (Tarragona); Francisco Rodilla (Teruel); Lucas Lorduy, Carmen Mas, Juan P. Ordovás, José L. Póveda (Valencia); Ana M. Espeia (Vitoria); Carmen Floristan (Vizcaya); and Javier Cerezo (Glaxo-Wellcome, Spain).
98-OA-007. Codina C, Trilla A, Riera N, Tuset M, Carne X, Ribas J, Asenjo M-A, the Hospital Pharmacy Antimicrobial Prophylaxis Study Group. Perioperative antibiotic prophylaxis in Spanish hospitals: results of a questionnaire survey. Infect Control Hosp Epidemiol 1999;20:436-439.

\section{REFERENCES}

1. Wenzel RP. Preoperative antibiotic prophylaxis. $N$ Engl J Med 1992;326:337-338.

2. Trilla A, Mensa J. Perioperative antibiotic prophylaxis. In: Wenzel RP, ed. Prevention and Control of Nosocomial Infections. 3rd ed. Baltimore, MD: Williams \& Wilkins; 1997:867-888.

3. Currier JS, Campbell H, Platt R, Kaiser AB. Perioperative antimicrobial prophylaxis in Middle Tennessee, 1989-1990. Rev Infect Dis 1991;13(suppl 10):S874-S878.

4. Kappstein I, Daschner FD. Use of perioperative antibiotic prophylaxis in selected surgical procedures-results of a survey in 889 surgical departments in German hospitals. Infection 1991;19:391-394.

5. McGowan JE. Cost and benefit of perioperative antimicrobial prophylaxis: methods for economic analysis. Rev Infect Dis 1991;13(suppl 10): $\mathrm{S} 879-\mathrm{S} 889$.

6. Vaque J, Rosselló J, Trilla A, Monge V, Garcia-Caballero J, Arribas JL, et al. Nosocomial infections in Spain: results of five nationwide serial prevalence surveys (EPINE Project, 1990 to 1994). Infect Control Hosp Epidemiol 1996;17:293-297.

7. Classen DC, Evans RS, Pestotnik SL, Horn SD, Menlove RL, Burke OP The timing of prophylactic administration of antibiotics and the risk of surgical-wound infection. N Engl J Med 1992;326:281-286.

8. Dellinger EP, Gross PA, Barrett TL, Krause PJ, Martone WJ, McGowan $\mathrm{JE} \mathrm{Jr}$, et al, Quality standard for antimicrobial prophylaxis in surgical procedures. Infect Control Hosp Epidemiol 1994;15:182-188.

9. Kreter B, Woods M. Antibiotic prophylaxis for cardiothoracic operations. Meta-analysis of thirty years of clinical trials. J Thorac Cardiovase Surg 1992;104:590-599.

10. Doebbeling BN, Pfaller MA, Kuhns KR, Massanari RM, Behrendt DM, Wenzel RP. Cardiovascular surgery prophylaxis: a randomized, controlled comparison of cefazolin and cefuroxime. J Thorac Cardiovasc Surg 1990;99:981-989.

11. Frantzides CT, Sykes A. A reevaluation of antibiotic prophylaxis in laparoscopic cholecystectomy. J Laparoendosc Surg 1994;4:375 378.

12. Platt R, Zucker JR, Zaleznik DF, Hopkins CC, Dellinger EP, Karchmer $\mathrm{AW}$, et al. Prophylaxis against wound infection following herniorrhaphy or breast surgery. J Infect Dis 1992;166:556-560.

\title{
TB Screening in Physicians' Offices
}

\section{Gina Pugliese, RN, MS Martin S. Favero, PhD}

Schulte and coinvestigators from CDC's Division of Tuberculosis Elimination assessed tuberculin skintesting practices of physicians after community-wide screening of 1,400 children exposed to a pediatrician with active TB in a medium-sized city in eastern Pennsylvania. A self-administered questionnaire was completed by 60 of 80 pediatricians and family practitioners seeing pediatric patients.
The 60 physicians had practiced a mean of 17 (range, 3-38) years, and only 1 did not do TB skin testing for pediatric patients. In total, the 59 physicians doing TB skin testing reported routinely tuberculin testing more than 900 children per month. Only 8 (14\%) of 59 physicians followed published guidelines for placement and reading of tuberculin tests. It was concluded that, in this community where a highly publicized TB case prompted massive pediatric screening, most physicians seeing children in private practice do not fol- low standard TB skin-testing guidelines. Increased understanding of how private-practice physicians learn about and decide to use recommended standards is needed if tuberculin tests are to be performed correctly and diagnosed appropriately.

FROM: Schulte JM, Moore M, Kistler V, Margraf P, Christman R, Valway SE, et al. Tuberculosis screening in private physicians' offices, Pennsylvania, 1996. Am J Prev Med 1999;16:178-181. 